\title{
Application of a projective method for the assessment of children's dental fear
}

\author{
Alessandra Maia Castro, $\mathrm{PhD}_{1}$, Denise Ascenção Klatchoian, $\mathrm{PhD} ._{2}$, \\ Marcelle Danelon, $\mathrm{PhD}_{3}$, Luhana Santos Garcia, MSc. ${ }_{3}$, Célio Percinoto, PhD. ${ }_{3}$ \\ ${ }_{1}$ Department of Pediatric Dentistry and Public Health, Federal University of Uberlândia, Minas Gerais, Brazil. \\ ${ }_{2}$ Department of Pediatric Dentistry and Public Health, Federal University of São Paulo, Brazil. \\ ${ }_{3}$ Department of Pediatric Dentistry and Public Health, Araçatuba Dental School, São Paulo, Brazil.
}

Recibido: 2 de agosto del 2016 Aprobado: 24 de noviembre del 2016

*Autor de correspondencia: Célio Percinoto. Rua José Bonifácio, 1193. Vila Mendonça -Araçatuba - SP - Brazil. cEP: 16015-050. Tel: 55 (18) 3636-3235. Correo electrónico: percinoto@foa.unesp.br

Cómo citar este artículo: Castro AM, Klatchoian DA, Danelon M, Garcia LS, Percinoto C. Application of a projective method for the assessment of children's dental fear. Rev Nac Odontol. 2017;13(25):11-19. doi: http://dx.doi.org/10.16925/ od.v13i25.1705

Abstract. Aim: The aim of this study was to assess children's dental fear by using the Children's Dental Fear Picture Test ( $\mathrm{CDFP}$ ) projective technique. Material and Methods: Forty patients from a pediatric dental clinic, between 5 and 9 years old, took part in this study. At first, the CDFP was applied to the children. This method has three subtests and its overall assessment classifies children as fearful, non-fearful and uncertain. Results: The children answered the Children Fear Survey Schedule-Dental Subscale (CFSS-DS). The results showed that CDFP has inter-examiner reliability and a significant correlation with the CFss-Ds. Conclusion: According to the Children's Dental Fear Picture test (CDFP), the majority of children in this study did not present fear of dental treatment. The CDFP was valid, according to its significant correlation with the CFSs-DS.

Keywords: child behavior, dental fear, pediatric dentistry, psychology. 
doi: http://dx.doi.org/10.16925/od.v13i25.1705

\section{(C) $(1)(9)$}




\section{Clinical significance}

Based on the literature review carried out and the results, important aspects related to the fear of children to dental care were revealed. However, when applying the instruments, limitations and difficulties were observed, which should be seen as future challenges to be overcome, which will only be possible with the integration of knowledge between Psychology and Pediatric Dentistry.

In spite of recent technological advances in Dentistry, fear and anxiety are still common in both children and adults and they are significant barriers to dental treatment. Fear and anxiety may reduce the patient's cooperation with treatment, negatively influence their adaptation, increase pain perception, enhance the difficulty of procedures and, furthermore, cause greater tension on the professional [1-2]. Moreover, the patients become more resistant towards following preventive guidance and present a greater tendency to delay, miss or cancel scheduled appointments [3-4]. As a result of fear and anxiety, many individuals avoid dental assistance, and then, the patient is caught in a vicious circle in which fear, pain, sense of inferiority and guilt prevent them from receiving adequate treatment. Thus, there is an aggravation of oral problems and the patient is submitted to a more complex and painful treatment. As a result, the feelings of fear and anxiety strengthen [5-9].

However, the application of instruments for assessing fear and anxiety, such as behavior ratings, psychometric tests, projective methods and physiological techniques, are not part of the routine of a dental clinic $[2,10]$. The use of these resources gains importance in the area of Pediatric Dentistry since dental fear, when acquired in infancy, persists throughout the adolescence and reflects in the individual's reactions and attitudes at an adult age [11-13].

Therefore, the aims of this study was to assess children's dental fear using Children's Dental Fear Picture Test (CDFP), a projective test, and checking the validity of this method through its correlation with the Children's Fear Survey Schedule-Dental Subscale (CFSs-Ds) [14-15].

\section{Material and methods}

This study was approved by the Research Ethics Committee of the School of Dentistry of
Araçatuba-State University Júlio de Mesquita Filho (Process: 1491/2003), and also by the Research Council of the Faculty of Dentistry of the Federal University of Uberlandia. After that, the project was carried out in accordance with Resolution 196 of the Brazilian Health Council.

At the Pediatric Dental Clinic, 64 children aged 5 to 9 years, who received curative dental assistance, were initially selected. The patients did not present any visual, hearing or mental limitation that would have prevented them from participating in this research.

At the clinic's waiting room, an initial contact was made with the mothers and their children with the purpose to explain the research's aim and methodology. In the face of the mother's acceptance, the consent form was signed and a day for the test to be applied at the patient's home was scheduled.

The researcher went to the child's home and, after providing additional explanation about the research, applied the Children's Dental Fear Picture Test (CDFP). This test was presented to the child as an interview, recorded on $\mathrm{K} 7$ tapes, in order to find out their opinion about dental treatment. The mothers were instructed not to interrupt or express their opinion about the given replies.

The CDFP was developed by Klingberg and Hwang [16] in Sweden and, after obtaining their permission to use the test with Brazilian children, all test material was sent to the researchers. CDFP consists of three subtests, which are described below:

\section{Children's Dental Fear Picture Test-Dental Settings (CFPP-DS)}

It consists of a set of ten pictures of animals in different dental care situations. The pictures were presented separately to the child, who was encouraged to tell a story about each picture. Then, each one of the ten pictures was assessed according to the story narrated, based on the following criteria:

1. Fearful: cautious children, very reluctant and hesitant to tell stories. The stories were characterized by the absence of details and imagination with long periods of silence. The animals in the pictures were described as if they felt strange, alone or afraid. Some children could add that they had felt like that in similar situations. 
2. Non-fearful: the children told the stories in an entertaining way, describing details, using their imagination and often with the enumeration of objects in pictures. The animals were described as being the center of attention, and important characters during the treatment.

3. Uncertain: the children that were not classified in the two previously mentioned groups due to their lack of concentration, preventing the researcher from making the assessment.

When all ten pictures were assessed, a final assessment was made and the category with highest score determined the classification of the child into the following criteria: fearful, non-fearful and uncertain.

\section{Children's Dental Fear Picture Test- Pointing Pictures (CDFP-PP)}

It is presented in two versions: one for girls and one for boys. Each version contains a set of five illustrations of children in different situations related to dental treatment. Each one presents two pictures of children expressing opposed reactions: one happy, non-fearful; the other sad, afraid. Below each picture, there were two circles, a total of four, which correspond to different scores: 1 (very happy and without any fear); 2 (feeling well and not afraid); 3 (feeling a little afraid); and 4 (feeling very afraid). For each one, the researcher told a story explaining the pictures and then asked the children to answer verbally and point to the circle that best corresponded to what they felt in a similar situation. Thus, the final assessment was based on the sum of the points of the five illustrations, with scores ranging from five to twenty and, according to the score obtained; the children were classified into one of the three categories:

- Fearful: total score equal to or higher than 12.

- Non-fearful: total score equal to or less than 11.

- Uncertain: the child's behavior did not permit the researcher's assessment.

\section{Children's Dental Fear Picture Test-Sentence Completion Task}

It includes a list of fifteen incomplete sentences. The researcher instructed the child to complete each sentence verbally after reading each one of them.
The general impression of the words or phrases used to complete the fifteen sentences allowed their classification in the following three categories:

- Fearful: the answers were predominantly negative (pain, fear, strange, bad, etc...)

- Non-fearful: the phrases or words were predominantly positive (fun, nice, happy, good, etc...)

- Uncertain: the child's behavior did not permit the researcher's assessment or the sentences were contradictory.

After the application of the three subtests, an overall assessment was performed based on the classification obtained in each one of them, and the category with the highest scores determined the child's final assessment as fearful, non-fearful or uncertain.

The CDFP was applied and analyzed by one dentist. In order to test interexaminer reliability, another professional, a specialist in Pediatric Dentistry, guided by the researcher, assessed the results using the tape recordings and written notes.

The child's behavior during the application of the test was analyzed according to the guidelines of the manual proposed by Klingberg and Hwang [17], and classified into the following categories: shyness, reluctant cooperation, agitation, tension/ stress, social acceptance, and without comments.

After CDFP application, the child was asked to answer the Children's Fear Survey ScheduleDental Subscale (CFSS-DS) [18]. This test is composed of fifteen items with five alternative answers each, with the following scores: 1 (fearless), 2 (a little fearful), 3 (fearful), 4 (quite fearful) and 5 (very fearful). Thus, the sum of the answers could range from 15 to 75 , allowing the children to be assessed as not afraid (sum of scores equal to or less than 37) or afraid (sum of scores equal to or above 38 ).

\section{Statistical analysis}

The Spearman Coefficient of Correlation by Posts was applied to assess correlations between the results of the three subtests and the overall assessment of the CDFP. The Chi-Square test was applied, followed by the Coefficient of Contingency $\mathrm{C}$ to assess the agreement between the two examiners that analyzed the CDFP and to check the correlation between the projective method and the self-report 
test. Statistical significance was established at $5 \%$ in a bilateral test.

\section{Results}

Only forty children participated in the study, twenty-four of the children initially selected, did not attend for various reasons, such as the child's refusal to seek the mother, incompatibility with the agenda of an interview, change of city or impossibility to locate the residence. The children had an average age of 7.4 years, distributed equally among the male and female genders. Twenty-three children were 5 to 7 years and seventeen, 8 to 9 years. The other twenty-four initially selected children did not participate in this study for several reasons.

In CDFP-DS, $30 \%$ of the children were assessed as fearful, $50 \%$ as non-fearful and $20 \%$ as uncertain. The CDFP-PP revealed that $22.5 \%$ of the participants were fearful, $70 \%$ non-fearful and $7.5 \%$ were uncertain. The CDFP-SC showed that $25 \%$ of the children had fear, $50.0 \%$ were assessed as being non-fearful and $25 \%$ as uncertain. In the overall assessment, it was found that 10 children (25\%) were assessed as fearful, $24(60 \%)$ did not present dental fear and $6(15 \%)$ were classified in the uncertain category (Table 1$)$.
The results of the three subtests and the overall assessment presented significant positive correlations.

The percentage agreement between the two examiners for CDFP-DS was $72.5 \%, 90 \%$ for CDFP-PP and $62.5 \%$ for the third subtest. In the overall assessment an interexaminer agreement of $82.5 \%$ was found. The interexaminer correlation was considered to be significant both for the three subtests and for the overall assessment, demonstrating that there was agreement between the two examiners.

The children aged 5 to 7 years presented higher scores of shyness behavior, reluctant cooperation and agitation when compared to those aged 8 to 9 years. Non of the children aged 5 to 7 years was included in the category of social acceptance (Table 2).

Table 3 demonstrates that there was a significant correlation in the overall assessment of the Children's dental Fear Picture Test with the results of the Children's Fear Survey Schedule-Dental Subscale.

\section{Discussion}

This work is a preliminary pilot study designed to test the reliability and validity of the CDFP test.

Table 1. Distribution of the number and percentage of children assessed as fearful, non-fearful or uncertain with the Children's Dental Fear Picture Test, according to age range

\begin{tabular}{lccccc}
\hline \multicolumn{1}{c}{ CDFP } & Age & Fearful & Non-fearful & Uncertain & Total \\
\hline \multirow{3}{*}{ CDFP-DS } & $5-7$ years & $6(26.08 \%)$ & $10(43.48 \%)$ & $7(30.44 \%)$ & $23(100 \%)$ \\
& $8-9$ years & $6(35.3 \%)$ & $10(58.82 \%)$ & $1(5.88 \%)$ & $17(100 \%)$ \\
& Total & $12(30 \%)$ & $20(50 \%)$ & $8(20 \%)$ & $40(100 \%)$ \\
CDFP-PP & $5-7$ years & $5(21.74 \%)$ & $15(65.21 \%)$ & $3(13.05 \%)$ & $23(100 \%)$ \\
& $8-9$ years & $4(23.53 \%)$ & $13(76.47 \%)$ & $0(0 \%)$ & $17(100 \%)$ \\
\hline \multirow{3}{*}{ CDFP-DS } & Total & $9(22.5 \%)$ & $28(70 \%)$ & $3(7.5 \%)$ & $40(100 \%)$ \\
& $5-7$ years & $5(21.74 \%)$ & $10(43.48 \%)$ & $8(34.78 \%)$ & $23(100 \%)$ \\
& $8-9$ years & $5(29.4 \%)$ & $10(58.82 \%)$ & $2(11.78 \%)$ & $17(100 \%)$ \\
Overall assessment & Total & $10(5 \%)$ & $20(50 \%)$ & $10(25 \%)$ & $40(100 \%)$ \\
\hline
\end{tabular}

Source: own work 
Table 2. Distribution of the number and percentage of children, according to behavior during the application of the CDFP classified by age range

\begin{tabular}{lcc}
\hline \multicolumn{1}{c}{ Behavior } & $\begin{array}{c}\text { Children } \\
\text { 5-7 years }\end{array}$ & $\begin{array}{c}\text { Children } \\
\text { 8-9 years }\end{array}$ \\
\hline Shyness & $7(87.5 \%)$ & $1(12.5 \%)$ \\
Reluctant cooperation & $6(66.6 \%)$ & $3(33.4 \%)$ \\
Agitation & $3(75 \%)$ & $1(25 \%)$ \\
Tension/Stress & $2(40 \%)$ & $3(60 \%)$ \\
Social acceptance & $0(0 \%)$ & $5(100 \%)$ \\
Without comments & $5(55.5 \%)$ & $4(44.4 \%)$ \\
\hline Total & $23(57.5 \%)$ & $17(42.5 \%)$ \\
\hline
\end{tabular}

Source: own work

Table 3. Values of $\mathrm{X}^{2}$ and $\mathrm{C}$ regarding to the application of the Chi-Square Test and Coefficient of Contingency $\mathrm{C}$, to the results of CDSS-DF and CDFP

\begin{tabular}{ccc}
\hline Analyzed variables & $\mathrm{X}^{2}$ & $\mathrm{C}$ \\
CDFSS-DS x CDFP & 8.53 & 0.42 \\
\hline
\end{tabular}

Source: own work

Critical value $\mathrm{X}^{2}=5.99$ for degrees of freedom $=2, \mathrm{p}<0.05$

The CDFP was proposed by Klingberg and Hwang [16] for the purpose of obtaining information that could complement diagnosis and provide understanding of anxiety in children.

The study was carried out at the patient's home, outside of the dental environment, as it was one of the requirements of the CDFP manual [17]. This option is probably justified by the nature of the test, which demands concentration of both children and interviewer, and takes long time to apply, around forty-sixty minutes. The home interview also avoided that appointments were missed, allowing children to be individually assessed in their own environment. As the CDFP demands the children's intense participation, their refusal to reply to the test due to shyness, difficulty to understand or incapability of concentrating, led to the exclusion of some patients from the sample.

Although the CDFP is a test, it was not noticed as such by the children; and was actually seen as an interviewing game in which they played the main role and even without noticing it, their spontaneous stories revealed data about their emotions regarding dental treatment.

In CDFP-DS, pictures of different animals were used, which did not prevent the children from identifying themselves with the situations when telling the stories and interpreting them as their own experiences, projecting their fear and anxiety into these pictures. It is important to point out that even when they did not recognize some of the animals represented because they did not know or had difficulty understanding them, the children were not inhibited and continued telling stories. Perhaps, it would be important to adapt the pictures, in order to make them more suitable to our reality.

In CDFP-PP, the child was encouraged to select one of the pictures in which he or she could identify an expression similar to his or her own in the same situation. In this subtest, as scores were attributed, classification became more objective. However, 7.5 $\%$ of the children that expressed doubt or replied in a contradictory way were assessed as uncertain (Table 1).

CDFP-SC consisted of completing sentences, and of the fifteen sentences, nine were related to dentistry, revealing general aspects of the child's perception of dental assistance. The words and phrases most frequently used by $25 \%$ of the children assessed as fearful were: pain, sad, don't like, unpleasant, bad and fear. In constrast, the replies of $50 \%$ of the non-fearful children were predominantly positive, with words such as: nice, fun, happy, pleasant, good, cheerful. The children classified under the "uncertain" category (25\%), most frequently presented changes in behavior, compromising the examiner's assessment (Table 1).

The results obtained in subtests I, II and III in the overall evaluation of the CDFP were similar to the values obtained by Klingberg and Hwang [16], as well as the positive correlation among the three subtests and the overall assessment, in spite of cultural and socioeconomic differences, sample size and criteria selection used [14-15].

The CDFP assessment is very subjective; however, the percentage of inter-examiner agreement ranged from moderate to high. CDFP-PP obtained the highest agreement (90\%), followed by the CDFP-DS (72.5\%), and at last, the sentence-completing task (62.5\%). These results were different from those obtained by Klingberg and Hwang [16], who found a lower percentage agreement for the first subtest $(81.48 \%)$ when compared to the 
values obtained in the other two subtests (85.19 $\%)$. Inter-examiner agreement found in the overall assessment was $82.5 \%$, while the value found by Klingberg and Hwang [16] was $88.89 \%$.

Furthermore, in relation to the inter-examiner agreement, a significant correlation was found, indicating agreement between the assessments of the CDFP, even considering that only one examiner was present at the time the test was applied, and the second examiner had the notes and recordings of the first and did not have the same degree of interaction and direct contact with the child. Klingberg and Hwang [16] also found this inter-examiner agreement, which permits the suggestion that this projective method presents reliability and can be administered by different professionals, obtaining similar results.

The behavioral assessment played an important role, as it was observed that shyness, reluctant cooperation and agitation were more common in children aged 5 to 7 , and they were assessed with higher scores as uncertain in the three subtests and CDFPoverall assessment. Thus, it is reasonable to suppose that age had an influence on the test assessment, since the ability to understand, the level of development and maturity of these children may have interfered in the results [19-20]. Moreover, for those children aged 8 to 9 , the most commonly observed behavior was social acceptance (Table 2), which is in accordance with the data obtained by Klingberg and Hwang $[14,16]$.

In comparison to other methods available in the literature to assess dental anxiety, like the Venham Picture Test (VPT) and the Visual Analogical Scale of Faces [3], the CDFP presents some peculiarities, such as the impossibility of its application on very young children, due to the limits imposed by their vocabulary and low capacity to concentrate, also, its administration has not been indicated in the dentistry environment. In contrast, the VPT and the Visual Analogical Scale are simple instruments, quickly administered, also in very young children, used to identify the level of anxiety before, during or after a dental session, allowing the professional to workout strategies for behavioral management or adopt techniques for reliving anxiety [21]. However, none of these methods appreciates so much the infant's emotions and perception of dental assistance as the CDFP does.

For innumerable reasons, children may not have sufficient capacity to recognize and interpret physiological and cognitive manifestations of anxiety; therefore, assessments of fear and anxiety frequently concentrate on the behavioral component of fear. However, this method of evaluation requires examiners to be trained in order to guarantee reliability and its clinical use is frequently inefficient $[18,22-23]$.

The psychometric techniques are objective as the attribution of scores is allowed. However, there is an inherent subjectivity in these techniques, since the replies depend on the subjective process of each individual. Thus, the implications of the replies may be completely obvious, leading the child to select the least compromising alternative [24]. In contrast to the structured form of the psychometric techniques, the projective methods present flexibility of replies, allowing different interpretations of the results. The main advantage of this method relates to its capacity to deceive the conscious replies of individuals, enabling the examiner to have access to important psychological information, like impulses and conflict, fear and anxiety [14]. Is is more difficult to abstract the replies to a projective test than the scores obtained in psychometric techniques [25].

The Children's Fear Survey Schedule-Dental Subscale (CFss) is the one which is most frequently administered to children to estimate the prevalence of fear, record the differences among control and experimental groups and, also, select children with and without fear of dental treatment. This finding matches with other studies [15, 18, 26-29].

The application of two different instruments to analyze the same variable is justified by individual variations in the manifestation of anxiety and to check the validity of the projective method. Thus, the significant correlation between self-report and the projective tests indicates that this is a valid instrument for assessing infant fear of dental treatment (Table 3). Using these tests, dental surgeons may be able to distinguish children who need more attention and decide on a more appropriate approach [14], thus establishing control and trust during the consultation, which will only be possible through better communication between professional and patient, therefore transforming the children's negative attitude, composed of doubts, suspicions and fears, into pleasant imagination [30].

One of the limitations of the study is to require the presence of a professional in the field of psychology, because as mentioned previously, fear and 
anxiety are often concentrated in the behavioral components of children, thus trained professionals would aid in the analysis of the results.

Limitations and difficulties were observed when applying the instruments. These should be approached as future challenges to be overcome, which will only be possible with knowledge integration between Psychology and Pediatric Dentistry. According to the Children's Dental Fear Picture Test (CDFP), the majority of children in this study did not present fear of dental treatment. The CDFP was valid,according to its significant correlation with the CFSs-DS.

\section{References}

[1] Ramos-Jorge ML, Marques LS, Pavia SM, Serra-Negra JM, Pordeus IA. Predictive factors for child behaviour in the dental environment. Eur Arch Paediatr Dent. 2006;7(4):253-7.

[2] Strom K, Ronneberg A, Skaare AB, Espelid I, Willumsen T. Dentists' use of behavioural management techniques and their attitudes towards treating pediatric patients with dental anxiety. Eur Arch Paediatr Dent. 2015;16(4):349-55.

[3] Del Gaudio DJ, Nevid JS. Training dentally anxious children to cope. J Dent Child. 1991; 58(1):31-7.

[4] Kleiman MB. Fear of dentists as an inhibiting factor in children's use of dental services. J Dent Child. 1982;49(3):209-13.

[5] Abrahamsson KH, Berggren U, Hakeberg M, Carlsson SG. Phobic avoidance and regular dental care in fearful dental patients: a comparative study. Acta Odontol Scand. 2001;59(5):259-73.

[6] Berggren U, Meynert G. Dental fear and avoidance: causes, symptoms, and consequences. J Am Dent Assoc. 1984;109(2):247-51.

[7] Milgrom P, Weinstein P. Dental fears in general practice: new guidelines for assessment and treatment. Int Dent J. 1993;43(1):288-93.

[8] Brukiene V, Aleksejuniene J, Balciuniene I. Is dental treatment experience related to dental anxiety? A croos-sectional study in Lithuanian adolescents. Stomatologija. 2006;8(4):108-15.

[9] Nuvvula S, Kamatham R., Challa R., Asokan S. Reframing in dentistry: Revisited. J Indian Soc Pedod Prev Dent. 2013;31(3):165-8.

[10] Dailey YM, Humphris GM, Lennon M. The use of dental anxiety questionnaires: a survey of a group of U.K. dental practioners. Br Dent J. 2001;190(8): 450-3.
[11] Aartman IHA, Everdigen TV, Hoogstraten J, Schuurs AH. Self-report measurements of dental anxiety and fear in children: a critical assessment. J Dent Child 1998;65:252-8.

[12] Paryab, M, Hosseinbor M. Dental anxiety and behavioral problems: A study of prevalence and related factors among a group of Iranian children aged 6-12. Journal of J Indian Soc Pedod Prev Dent. 2013;31(2):82-6.

[13] Xia B, Wang C, Ge L. Factors associated with dental behaviour management problems in children aged 2-8 years in Beijing, China. Int J Paediatr Dent. 2011;21(3):200-9.

[14] El-Housseiny AA, Farsi NM, Alamoudi, NM, Bagher SM, El Derwi D. Assessment for the Children's Fear Survey Schedule-Dental Subscale, J Clin Pediatr Dent. 2014;39(1):40-46.

[15] Bajric E, Kobaslija S, Juric H. Reliability and validity of Dental Subscale of the Children's Fear Survey Schedule (CFss-Ds) in children in Bosnia and Herzegovina. Bosn J Basic Med Sci. 2011;11(4):214-8.

[16] Klingberg G, Hwang CP. Children's Dental Fear Picture Test (CDFP): a projective test for the assessment of child dental fear. J Dent Child. 1994;61(2):89-96.

[17] Klingberg G, Hwang CP. Children's Dental Fear Picture Test: Manual. Götebor: University of Göteborg; 1993. $25 \mathrm{p}$.

[18] Cuthbert MI, Melamed BG. A screening device: children at risk for dental fears and management problems. J Dent Child. 1982;49(6):432-6.

[19] Rantavuori K. Factors associated with different measures of dental fear among children at different ages. J Dent Child. 2009;76(1):13-9.

[20] Suprabha BS, Rao A, Choudlhary S, Shenoy R. Child dental fear and behavior: the role of environmental factors in a hospital cohort. J Indiano Soc Pedod Dent Prev. 2011;29(2):95-101.

[21] Kilinç G, Akay A, Eden E, Sevinç N, Ellidokuz H. Evaluation of children's dental anxiety levels at a kindergarten and at a dental clinic. Braz Oral Res. 2016;30(1):1-8

[22] Newton JT, Buck DJ. Anxiety and pain measures in dentistry: a guide to their quality and application. J Am Dent Assoc. 2000;31(10):1449-57.

[23] Wogelius P, Poulsen S, Sorensen T. Prevalence of dental anxiety and behavior management problems among six to eight years old Danish children. Acta Odontol Scand. 2003;61(3):178-83.

[24] Klepsch M, Logie L. Children draw and communicate: an introduction to projective uses of children's drawings of the human figure. Porto Alegre: Artes Médicas; 1984. 204 p. 
[25] Lilienfeld SO, Wood JM, Garb HN. The scientific status of projective techniques. Psychol Sci Publ Interest. 2000;1(2):27-66.

[26] Klingberg G, Berggren U, Norén G. Dental fear in an urban Swedish child population: prevalence and concomitant factors. Community Dent Health. 1994;11(4):208-14.

[27] McComb M, Koenigsberg SR, Broder HL, Houpt $M$. The effects of oral conscious sedation on future behavior and anxiety in pediatric dental patients. Pediatr Dent. 2002;24(3):207-11.

[28] Raadal M, Milgrom P, Weinstein P, Mancl L, Cauce AM. The prevalence of dental anxiety in children from low-income families and its relationship to personality traits. J Dent Res. 1995; 74(8):1439-43.
[29] Raj S, Agarwal M, Aradhya K, Konde S, Nagakishore V. Evaluation of Dental Fear in Children during Dental Visit using Children's Fear Survey Schedule-Dental Subscale. Int J Clin Pediatr Dent. 2013;6(1):12-5.

[30] Abrahamsson KH, Hakeberg M, Stenman J, Ohrn K. Dental beliefs: evaluation of the swedish version of the revised dental beliefs survey in different patient groups and in a non-clinical student sample. Eur J Oral Sci. 2006;114(3):209-15. 